\title{
Sex differences in urea breath test results for the diagnosis of Helicobacter pylori infection: a large cross-sectional study
}

\author{
Ido Eisdorfer ${ }^{1}$, Varda Shalev ${ }^{1,2}$, Sophy Goren ${ }^{1}$, Gabriel Chodick ${ }^{1,2}$ and Khitam Muhsen ${ }^{1 *}$ (i)
}

\begin{abstract}
Background: Helicobacter pylori causes peptic ulcer disease and gastric cancer only in a subset of infected persons. Sex differences were shown in results of urea breath test (UBT), a commonly used test for the diagnosis of H. pylori infection. However, factors that might explain these differences, or affect UBT values, are not fully understood. We examined differences in UBT values between H. pylori-infected men and women while adjusting for background characteristics such as age, body mass index (BMI), and smoking.

Methods: A cross-sectional study was undertaken using coded data from the computerized database of Maccabi Health Services in Israel. Included were adults examined for UBT during 2002-2012 and were found H. pylori positive (UBT > 3.5\%o). Multivariable linear mixed models were performed to assess the relationship between sex and UBT quantitative results, while adjusting for background characteristics.

Results: A total of 76,403 patients were included (52\% of examined patients during the study period). Adjusted mean UBT value was significantly higher in women $33.8 \%$ ( $95 \% \mathrm{Cl} 33.4,34.1)$ than in men $24.9 \%$ ( $95 \% \mathrm{Cl} 24.5,25.3)$. A significant $(P<0.001)$ interaction was found between sex and smoking, showing diminished sex-differences in UBT results in smokers. Adjusted mean UBT values increased significantly with age and decreased with BMl, and it was higher in people who lived in low vs high socioeconomic status communities and lower in smokers vs non-smokers.

Conclusions: Systemic differences exist between men and women in quantitative UBT results. Host-related and environmental factors might affect UBT quantitative results. These findings have clinical implications regarding confirmation of the success of $H$. pylori eradication after treatment in various subgroups.
\end{abstract}

Keywords: H. pylori infection, Urea breath test, Sex differences, Smoking

\section{Background}

Helicobacter pylori colonizes the gastric mucosa and causes chronic gastritis. Most H. pylori-infected persons remain asymptomatic, but some might develop peptic ulcer disease and gastric cancer [1-4]. Men have higher risk for peptic ulcers [5] and gastric cancer $[6,7]$ compared to women, although the difference between sexes in H. pylori infection prevalence is small [8].

$H$. pylori invasive detection methods are based on gastric biopsy and include culture, histology, and rapid urease test (reviewed in $[9,10]$ ). Among the non-invasive tests, urea

\footnotetext{
* Correspondence: kmuhsen@post.tau.ac.il; khitam15@yahoo.com

'Department of Epidemiology and Preventive Medicine, School of Public Health, Sackler Faculty of Medicine, Tel Aviv University, Ramat Aviv, 69978 Tel Aviv, Israel

Full list of author information is available at the end of the article
}

breath test (UBT) is highly accurate [11]; it is recommended for the diagnosis of $H$. pylori in test-and-treat strategy and for the confirmation of $H$. pylori eradication [12].

UBT is based on urease activity of $H$. pylori and its ability to hydrolyze orally ingested isotopically labeled urea $\left({ }^{13} \mathrm{C}\right.$ or ${ }^{14} \mathrm{C}$ urea) into ammonia and labeled carbon dioxide $\left(\mathrm{CO}_{2}\right)$, which is eventually exerted through the lungs in exhaled breath $[10,13]$. The amount of labeled carbon dioxide is measured as ${ }^{13} \mathrm{C}$ to ${ }^{12} \mathrm{C}$ ratio and expressed as delta over baseline (DOB) value. Typically, DOB of $3.5 \%$ or greater is employed to determine the presence of $H$. pylori infection, and some use a cutoff value of $5 \%$ [10]. DOB values were shown to be positively correlated with gastric $H$. pylori bacterial load or density and severity of gastritis [14-18]. 
Some studies reported significantly higher DOB values in $H$. pylori-infected females compared to infected males [19-22]; however, the explanation of these observations is not fully known. The aims of the current study were to examine differences in UBT results between $H$. pylori-infected men and women and to examine whether these differences might be explained or modified by sociodemographic and clinical characteristics, such as age, body mass index (BMI), and smoking.

\section{Methods}

\section{Study design and population}

A cross-sectional study was undertaken using anonymous data retrieved from the computerized database of Maccabi Health Services (MHS) Health Maintenance Organization (HMO). MHS is the second largest HMO in Israel with two million insured persons $(\sim 25 \%$ of the Israeli population). The source population comprised adults aged $\geq 25$ years who performed the ${ }^{13} \mathrm{C}$-UBT between 2002 and 2012. This referral sample included mainly persons with symptoms and complaints consistent with clinical indications for the diagnosis of $H$. pylori infection. Exclusion criteria were anti-H. pylori eradication therapy (according to purchases of medications) or proton pump inhibitors 4 weeks before the UBT, history of bariatric surgery, a prior diagnosis of gastric cancer, and diagnosis of other cancers within 2 years from the UBT. Information on cancer was obtained via linkage with Israel's National Cancer Registry.

\section{Data extraction and definitions}

Information was obtained on UBT result, birth date, sex, town of residence, and smoking (ever, never, and unknown). Age at the first UBT was grouped into five categories: $25-34,35-44,45-54$, and 65-95 years. Socioeconomic status (SES) was defined based on the socioeconomic rank of place of residence at the level of town, as defined by the Israel Central Bureau of Statistics [23]. The ranks are on a scale from 1 to 10 , with higher ranks representing a higher socioeconomic status. This aggregative socioeconomic index reflects a combination of basic characteristics of a specific geographical unit investigated, mainly financial resources of the residents, housing conditions, motorization level, education, and employment [23]. Communities with socioeconomic ranks of $1-5$ and 6-10 were classified as low and intermediate/high, respectively. BMI (weight in kilograms $(\mathrm{kg}) /$ height $^{2}$ in meters $(\mathrm{m})$ ) was categorized into the following categories: < 18.5, 18.5-24.9, 2529.9 , and $\geq 30 \mathrm{~kg} / \mathrm{m}^{2}$.

Patients with a UBT result of DOB $>3.5 \%$ were considered $H$. pylori positive. If more than one UBT was performed, we used the first test. The presence of peptic ulcer disease was defined based on the International
Classification of Diseases, 9th revision (ICD-9) and corresponding internal codes at MHS.

\section{Statistical analysis}

Student's $t$ test was used to examine differences in mean UBT values among infected persons according to sex, and one-way analysis of variance (ANOVA) was used to examine differences in UBT values according to age, BMI categories, SES, and smoking. Multivariable analyses were performed using mixed linear models to assess the relationship between sex and UBT values while controlling for other independent variables; interactions between sex and other independent variables were tested in these models. Pooled and sex-stratified analyses were performed. Two-tailed $P<0.05$ was considered significant. Data were analyzed using SPSS version 23 (IBM, Armonk, New York, USA).

\section{Ethical approval}

The study protocol was approved by the Helsinki committee of Assuta Medical Center and the ethics committee of Tel Aviv University. Since this was a retrospective study in which we used coded (anonymized) administrative data from electronic medical records, an exemption from informed consent was given by the Helsinki committee.

\section{Results}

During the study period, 146,864 persons $(60.7 \%$ females), with a mean age of 42.7 years (standard deviation (SD) 12.7), were referred to UBT and met the inclusion criteria. The mean age of men and women was 42.8 (SD 12.5) and 42.7 (SD 12.8), respectively, $P=0.6$. H. pylori infection (UBT $>3.5 \%$ ) was evident in 76,403 persons (52.0\%), and it was 52.9 and $51.5 \%$ in men and women, respectively. Men had a higher mean BMI than women, $26.6 \mathrm{~kg} / \mathrm{m}^{2}$ (SD 4.1) vs $25.5 \mathrm{~kg} / \mathrm{m}^{2}$ (SD 5.1), $P<0.001$, and were smokers more often compared to women, 19.5 vs $10.7 \%, P<0.001$. The distribution of SES was similar between men and women: 41.0, 26.3, and $26.3 \%$ of the men lived in low, intermediate, and high SES towns, respectively, vs $40.5,26.6$, and $26.5 \%$ of the women.

\section{Mean values of UBT results according to background characteristics}

Among $H$. pylori-infected persons, UTB results ranged from 3.51 to $175.0 \%$ with a mean DOB value of $30.2 \%$ (SD 20.9) and a median of $24.6 \%$ (interquartile range [IQR 24.8]). The mean UBT values were significantly higher in women than in men, 34.6\% (SD 22.8) and $23.6 \%$ (SD 15.4), respectively, with a mean difference of $11.0 \%$ o (95\% CI 10.7, 11.3); $P<0.001$. The median DOB value was 28.8\% (IQR 28.6) and 19.6\% (IQR 18.1) in women and men, respectively. 
Overall, the mean UBT values increased significantly $(P<0.001)$ with age by 3.7 units from $28.6 \%$ (SD 20.3) in the youngest age group to $32.3 \%$ (SD 22.4) in the oldest age group. Mean UBT values decreased as BMI increased $(P<0.001)$ by 9 units, from 36.5\% (SD 25.4) in persons with $\mathrm{BMI}<18.5 \mathrm{~kg} / \mathrm{m}^{2}$ to $27.2 \%$ (SD 18.1) in obese persons with $\mathrm{BMI} \geq 30 \mathrm{~kg} / \mathrm{m}^{2}$. Smokers had a lower mean UBT value compared to non-smokers, with a mean difference of 8.1 (95\% CI 7.7, 8.5) DOB units $(P$ $<0.001$ ) (Table 1).

A stratified analysis by sex showed that in men, the average UBT values increased by 5 units from $22.0 \%$ (SD 14.6) at the youngest age group 25-34 to $27.2 \%$ (SD 18.9) at age 65-95 years, while in women, the corresponding increase was 2.6 units from 33.1\%o (22.3) to $35.7 \%$ o 23.8$)$. The difference in UBT values between persons living in low vs intermediate/high SES communities was evident in women (2.1 units) more than in men (0.3 units). The difference according to BMI was found in both sexes, with significant interaction $(P=0.031)$, suggesting a reduced difference between sexes in obese persons. Differences in the mean UBT values according to smoking were also observed in both sexes, but among smokers, the gap in UBT values between men and women was reduced by 3 units $(P<0.001$ for interaction) (Table 1$)$.

In a pooled multivariable analysis that adjusted for baseline characteristics, $H$. pylori-infected women still

Table 1 Unadjusted mean DOB of ${ }^{13} \mathrm{C}-U B T$ values of $\mathrm{H}$. pylori-infected patients according to baseline characteristics

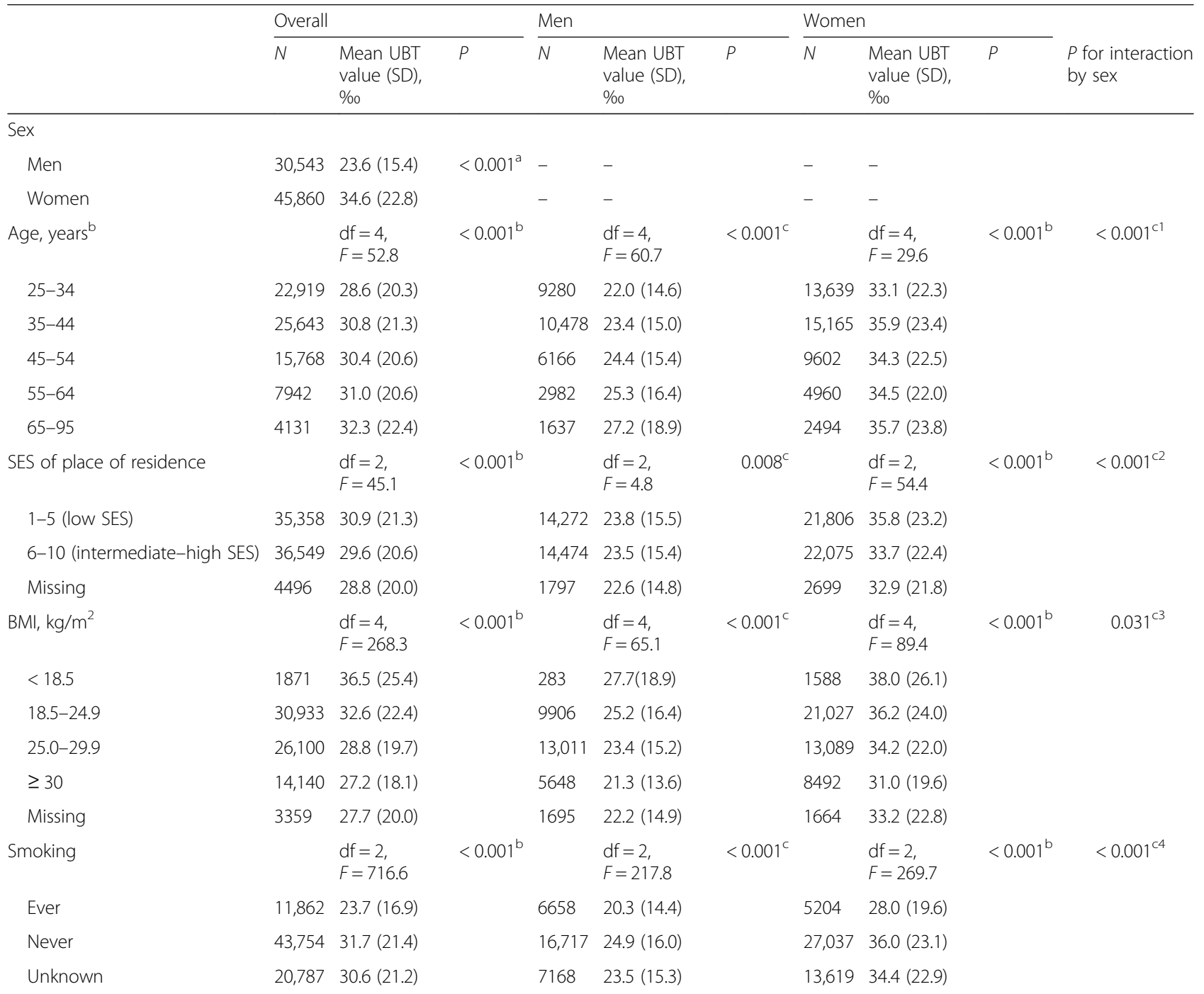

H. pylori infection was defined as delta ${ }^{13} \mathrm{C}-\mathrm{UBT}$ of $>3.5$ per thousand, see text for details

$B M I$ body mass index, $d f$ degrees of freedom, $D O B$ delta over baseline, $S D$ standard deviation, UBT urea breath test, SES socioeconomic status

${ }^{\text {a }} P$ value by Student's $t$ test; $t=-74.0, \mathrm{df}=76,385.8$

${ }^{\mathrm{b}} P$ value by ANOVA

${ }^{C} P$ values from linear mixed model assessing interaction between sex and each independent variable in separate models: ${ }^{1} \mathrm{df}=4, F=19.5 ;{ }^{2} \mathrm{df}=2, F=18.8 ;{ }^{3} \mathrm{df}=4$, $F=2.6 ;$ and ${ }^{4} \mathrm{df}=2, F=32.3$ 
had significantly $(P<0.001)$ higher mean UBT values than men, although the difference $(9.7 \%$ \% [95\% CI 9.0, 10.4]) in DOB units was reduced compared to unadjusted results. Additionally, the differences according to age groups, SES of place of residence, BMI, and smoking remained significant $(P<0.001)$ (Table 2$)$.

This model showed interactions $(P<0.001)$ between sex and other independent variables. Overall, women had a higher adjusted mean DOB than men in about 9.7 units; in women aged 35-44, the difference was increased by 1.3 units $(P=0.001)$, and in men aged $45-54,55-64$, and 65-95, the difference was reduced by $0.8(P=0.059), 1.1 \quad(P=0.045)$, and $1.3(P=0.074)$ units, respectively. In women who lived in low SES towns, the difference in UBT values increased by 1.8 units $(P<0.001)$. The difference between men and women in UBT values was reduced by 3.5 units $(P<$ 0.001) in smokers.

Table 2 Adjusted UBT values per thousand of H. pylori-infected patients according to baseline characteristics

\begin{tabular}{|c|c|c|}
\hline & $\begin{array}{l}\text { Estimate } \\
(95 \% \mathrm{Cl})^{*}\end{array}$ & $\begin{array}{l}\text { Adjusted mean } \\
\text { UBT value }(95 \% \mathrm{Cl})\end{array}$ \\
\hline Intercept & $\begin{array}{l}27.6 \\
(26.5,28.6)\end{array}$ & $\begin{array}{l}\text { Overall } 29.3 \\
(29.0,29.6)\end{array}$ \\
\hline \multicolumn{3}{|l|}{$\operatorname{Sex}^{\mathrm{a}}$} \\
\hline Men & 0 (reference) & $24.9(24.5,25.3)$ \\
\hline Women & $9.7(9.0,10.4)$ & $33.8(33.4,34.1)$ \\
\hline \multicolumn{3}{|l|}{ Age, years ${ }^{\mathrm{b}}$} \\
\hline $25-34$ & 0 (reference) & $26.4(26.1,26.8)$ \\
\hline $35-44$ & $2.1(1.5,2.7)$ & $29.2(28.8,29.6)$ \\
\hline $45-54$ & $3.4(2.7,4.0)$ & $29.4(29.0,29.8)$ \\
\hline $55-64$ & $4.2(3.3,5.0)$ & $30.1(29.5,30.6)$ \\
\hline $65-95$ & $5.8(4.7,6.9)$ & $31.6(30.9,32.3)$ \\
\hline \multicolumn{3}{|l|}{ SES of place of residence ${ }^{c}$} \\
\hline 1-5 (low SES) & $0.8(0.3,1.3)$ & $30.2(29.8,30.4)$ \\
\hline 6-10 (intermediate-high SES) & 0 (reference) & $28.5(28.1,28.8)$ \\
\hline \multicolumn{3}{|l|}{$\mathrm{BMI} \mathrm{kg} / \mathrm{m}^{2 \mathrm{~d}}$} \\
\hline$<18.5$ & 0 (reference) & $33.5(32.6,34.5)$ \\
\hline $18.5-24.9$ & $-2.8(-3.8,-1.8)$ & $30.7(30.5,31.0)$ \\
\hline $25.0-29.9$ & $-5.5(-6.4,-4.5)$ & $28.1(27.8,28.4)$ \\
\hline$\geq 30$ & $-8.6(-9.6,-7.6)$ & $24.9(24.6,25.3)$ \\
\hline \multicolumn{3}{|l|}{ Smokinge } \\
\hline Unknown & $-1.3(-1.9,-0.7)$ & $30.5(30.1,30.9)$ \\
\hline Ever & $-4.6(-5.2,-4.0)$ & $25.6(25.1,26.0)$ \\
\hline Never & 0 (reference) & $31.9(31.6,32.3)$ \\
\hline
\end{tabular}

$B M I$ body mass index, $C l$ confidence intervals, $D O B$ delta over baseline, UBT urea breath test, SES socioeconomic status

${ }^{*} P<0.001$ for all variables was obtained in type III tests of fixed effects. Denominators: degree of freedom (df) of all variables was 68,699 . Numerators: ${ }^{\mathrm{a}} \mathrm{df}=1, F=1685.2 ;{ }^{\mathrm{b}} \mathrm{df}=4, F=91.1,{ }^{\mathrm{c}} \mathrm{df}=2, F=122.2{ }^{\mathrm{d}} \mathrm{df}=4, F=276.7$; ${ }^{e} \mathrm{df}=2, F=414.7$
Multivariable analyses, conducted separately for men and women, showed that age, SES, BMI, and smoking were significant determinants of UBT results in both sexes (Table 3).

\section{Secondary analysis}

The mean values of UBT in uninfected men and women were similar, 0.71 (SD 0.60) and 0.76 (SD 0.56), respectively.

\section{Discussion}

We examined sex differences in $H$. pylori infection prevalence and values of UBT in positive persons, in a large referral sample of adults. The prevalence of $\mathrm{H}$. pylori infection in this sample was similar in men and women, 52.9 vs $51.5 \%$. Among $H$. pylori-infected individuals, the mean delta UBT value was significantly higher in women than in men, 34.6 and $23.6 \%$, respectively. This difference was slightly attenuated after adjustment for background characteristics, 33.8 and $24.9 \%$ in women and men, respectively, with adjusted mean difference of 9.7\% (95\% CI 9.0, 10.4).

UBT measures the amount of labeled $\mathrm{CO}_{2}$ exerted through the lungs in exhaled breath [10, 13]. Thus, beyond the presence of $H$. pylori urease that hydrolyzes the urea into ammonia and labeled $\mathrm{CO}_{2}$, factors affecting endogenous production of $\mathrm{CO}_{2}$ have an impact on UBT quantitative results. Endogenous production of $\mathrm{CO}_{2}$ depends much on basal metabolic rate, which differs according to sex and body surface area (a function of weight and height).

Although we adjusted for host-related and environmental factors including age, SES, smoking, and BMI, $H$. pylori-infected women still had higher UBT values compared to men, thus suggesting that these background characteristics account only partially for the sex differences in UBT values and that there must be additional contributing factors. Variation between men and women was shown in intragastric acidity and plasma gastrin concentration profiles [24]. Urease activity was shown to be increased in more acidic conditions [25-27]; therefore, sex differences in intragastric $\mathrm{pH}$ might contribute to sex differences in DOB values. Studies of Mongolian gerbils have shown that gastric mucosal cytokine and epithelial cell response to $H$. pylori infection differ between males and females, with skewed cytokine response in females towards T-helper 1 profile [28], in addition to difference in the magnitude of anti- $H$. pylori gastric cytokine responses [28]. Collectively, these observations support the possibility of the involvement of sex-specific immunological or hormonal factors on UBT values. Hormonal factors might affect gastric mucosal blood flow and thickness of mucus layer [29]; the role of these factors in variation in UBT values warrants exploration. 
Table 3 Adjusted UBT values of H. pylori-infected patients according to baseline characteristics by sex

\begin{tabular}{|c|c|c|c|c|}
\hline & \multirow{2}{*}{$\begin{array}{l}\text { Estimate }(95 \% \mathrm{Cl})^{\mathrm{a}} \\
\text { Men }\end{array}$} & \multirow{2}{*}{$\begin{array}{l}\text { Estimate }(95 \% \mathrm{Cl})^{\mathrm{b}} \\
\text { Women }\end{array}$} & \multicolumn{2}{|c|}{ Adjusted mean UBT value (95\% Cl of the mean) } \\
\hline & & & Men & Women \\
\hline Intercept & $27.6(25.9,29.5)$ & $37.2(36.0,38.4)$ & Overall $24.9(24.4,25.4)$ & Overall $33.7(33.3,34.2)$ \\
\hline \multicolumn{5}{|l|}{ Age, years } \\
\hline $25-34$ & 0 (reference) & 0 (reference) & $22.0(21.4,22.5)$ & $30.9(30.4,31.4)$ \\
\hline $35-44$ & $2.0(1.5,2.4)$ & $3.5(2.9,4.0)$ & $24.0(23.4,24.5)$ & $34.4(33.9,34.9)$ \\
\hline $45-54$ & $3.2(2.7,3.7)$ & $2.6(2.0,3.3)$ & $25.2(24.6,25.8)$ & $33.6(33.0,34.1)$ \\
\hline $55-64$ & $4.0(3.3,4.6)$ & $3.2(2.5,4.0)$ & $26.0(25.2,26.7)$ & $34.2(33.4,34.9)$ \\
\hline $65-95$ & $5.6(4.8,6.4)$ & $4.7(3.7,5.7)$ & $27.6(26.7,28.5)$ & $35.6(34.7,36.6)$ \\
\hline \multicolumn{5}{|l|}{ SES of place of residence } \\
\hline 1-5 (low SES) & $0.8(0.4,1.1)$ & $2.7(2.3,3.2)$ & $25.3(24.8,25.9)$ & $35.1(34.6,35.6)$ \\
\hline 6-10 (intermediate-high SES) & 0 (reference) & 0 (reference) & $24.6(24.0,25.1)$ & $32.4(31.9,32.8)$ \\
\hline \multicolumn{5}{|l|}{$\mathrm{BMI}, \mathrm{kg} / \mathrm{m}^{2}$} \\
\hline$<18.5$ & 0 (reference) & 0 (reference) & $29.1(27.2,30.9)$ & $38.1(36.9,39.3)$ \\
\hline $18.5-24.9$ & $-3.2(-5.0,-1.4)$ & $-2.6(-3.8,-1.4)$ & $25.8(25.5,26.2)$ & $35.4(35.0,35.8)$ \\
\hline $25.0-29.9$ & $-5.5(-7.3,-3.7)$ & $-5.4(-6.7,-4.2)$ & $23.5(23.2,23.9)$ & $32.6(32.2,33.1)$ \\
\hline $30+$ & $-7.7(-9.6,-5.9)$ & $-9.2(-10.5,-7.9)$ & $21.3(20.9,21.8)$ & $28.8(28.3,29.4)$ \\
\hline \multicolumn{5}{|l|}{ Smoking } \\
\hline Unknown & $-1.3(-1.7,-0.8)$ & $-1.7(-2.2,-1.2)$ & $25.6(25.0,26.2)$ & $35.3(34.8,35.8)$ \\
\hline Ever & $-4.6(-5.1,-4.1)$ & $-8.1(-8.8,-7.4)$ & $22.3(21.7,22.9)$ & $28.9(28.2,29.6)$ \\
\hline Never & 0 (reference) & 0 (reference) & $26.9(26.4,27.4)$ & $37.0(36.6,37.4)$ \\
\hline
\end{tabular}

$B M I$ body mass index, $D O B$ delta over baseline, $S D$ standard deviation, UBT urea breath test, SES socioeconomic status

${ }^{\mathrm{a}} P<0.001$ for all variables was obtained in type III tests of fixed effects. Denominators: degree of freedom (df) of all variables was 27,123 . Numerators: $\mathrm{df}=1(F=$ 16.7), 2 ( $F=192.9), 3(F=109.2)$, and $4(F=73.6)$ for SES of place of residence, smoking, BMI, and age, respectively

${ }^{\mathrm{b}} P<0.001$ for all variables was obtained in type III tests of fixed effects. Denominators: $\mathrm{df}$ of all variables was 41,573 . Numerators: $\mathrm{df}=1(F=148.2), 2(F=259.6), 3$ $(F=173.4)$, and $4(F=47.2)$ for SES of place of residence, smoking, BMI, and age, respectively

Previous studies on sex differences in UBT values among $H$. pylori-infected people have also showed higher mean values of about 5 to 10 units in females compared to males [19-22]. However, adjustment for background characteristics beyond age was limited in previous studies. Interestingly, in both $H$. pylori-infected men and women, the mean UBT values increased with age, but it decreased with increased BMI. Smokers had a significantly lower mean UBT result than non-smokers, as well as persons who lived in high/intermediate SES towns compared to those who lived in low SES towns.

It was proposed that the magnitude of DOB of UBT might serve as an indicator for the severity of gastric inflammation and $H$. pylori bacterial load in the stomach [14-18, 30]. Values of DOB reflect also urease enzyme activity in various gastric $\mathrm{pH}$ levels. It was shown that $H$. pylori does not survive at either acidic or alkaline environments [25, 27]. Intragastric $\mathrm{pH}$ plays an important role in the activity of urease of $H$. pylori; acidic conditions increase urease activity and the bacterium's survival [25-27]. Intragastric $\mathrm{pH}$ increases with the development of gastric atrophy [31]. Therefore, in the case of gastric atrophy, which develops with increased age, a decrease in DOB values would be expected. The increase in the severity of gastritis with age might explain the rise in DOB values with age, i.e., reflecting a greater gastric inflammation and activity of urease. The same might be applied to persons living in low SES communities, who usually acquire the infection at younger age compared to persons living in high SES communities [32, 33]. An additional or alternative explanation is that basal metabolic rate decreases with age [34, 35], thus leading the higher UBT values in older patients.

The absolute difference in UBT results in smokers and non-smokers infected with $H$. pylori was relatively large. The lower mean DOB values observed in smokers compared to non-smokers herein and by others [36] might be due to the harmful effects of smoking on gastric mucosa [37] and development of atrophic gastritis. Smoking is a known risk factor for peptic disease [36], atrophic gastritis [38], and gastric cancer [39]. Therefore, these findings suggest that interpretation of UBT results in smokers warrants attention.

The negative association of BMI with UBT values in both $H$. pylori-infected men and women is likely due to the differences in metabolic rate according to body size. H. pylori infection was shown to be associated with lower mean height [40]; thus, indirectly, it affects endogenous $\mathrm{CO}_{2}$ production. 
H. pylori infection prevalence was lower in patients who lived in intermediate/high SES towns (47\%) than those who lived in low SES towns (59\%), $P<0.001$, in agreement with previous reports $[41,42]$. Surprisingly, we found that SES of place of residence was also inversely related to UBT quantitative results. This suggests high gastric $H$. pylori bacterial load in persons who live in low SES communities due to more intense exposure to the infection. Since we employed an aggregative SES index of place of residence, our observation might indicate possible influence of environmental factors on UBT results, including air pollution that affects lung function [43, 44].

The clinical importance of higher UBT results in $H$. pylori-infected women than men is not fully clear. One might expect a higher disease risk in groups displaying greater DOB values. However, men are at greater risk for peptic ulcer disease than women [36]. However, women suffer more often from functional dyspepsia [45, 46]. The recent Maastricht V/Florence Consensus Report on the management and treatment of $H$. pylori indicated that $H$. pylori gastritis is a distinct cause of dyspepsia and thus is considered an organic disease [12], whereas Rome III consensus considered $H$. pylori-related dyspepsia as functional. The question of whether the sex differences in dyspepsia might be related to higher UBT values in women remains to be elucidated. Some studies have reported a higher rate of $H$. pylori eradication failures in women than in men $[47,48]$, while the opposite was shown in another study [49]. Moreover, higher UBT values prior to the administration of anti-H. pylori therapy are associated with increased likelihood of treatment failure [49]. A clinical trial that assessed the effect of cranberry juice on $H$. pylori eradication in patients who received triple therapy showed significantly higher eradication rates in women who received both cranberry juice and triple therapy compared to placebo beverage and triple therapy [50]. Such effect was not observed in men [50]. Collectively, these findings demonstrate the clinical significance of UBT quantitative results.

Our study has some drawbacks. We used data from a large HMO database, routinely collected for patients' clinical care. Data collecting methods on variables such as smoking and BMI may differ among medical staff members. Missing information on smoking status was evident in $27 \%$ of the study sample. In persons with $H$. pylori infection whose smoking status was unknown, the mean UBT values were similar to never smokers. Missing data on SES and BMI is low and seems quite random with low threat of bias.

Our study also has strengths. First is the use of a large population-based sample. Second is the employment of standard criteria for the classification of sociodemographic factors and $H$. pylori infection. Third, the UBT was performed in one laboratory throughout the study period. Lastly, our sample likely represents symptomatic persons, since only physicians can refer patients to UBT.

\section{Conclusion}

In summary, in a large referral sample, we demonstrated systemic differences between men and women in quantitative UBT results. In addition, host-related and environmental factors such as age, SES of place of residence, BMI, and smoking affect UBT quantitative results in $H$. pylori-infected people. Hence, inference from UBT quantitative results on $H$. pylori gastric bacterial load and severity of gastritis should be made with caution. Clinical implications of these findings relate to confirmation of $H$. pylori eradication success or failure following therapy in various subgroups, and our observations raise a question of whether cutoff values for UBT should be sex-specific.

\section{Acknowledgements}

This work was undertaken in partial fulfillment of the PhD requirements of Mr. Ido Eisdorfer at the Sackler Faculty of Medicine, Tel Aviv University. We would like to thank Ms. Racheli Katz from Maccabi Health Services for her support in retrieving the data from the computerized databases.

\section{Funding}

This study was partially funded by the Council for Higher Education, Israel (KM-PI).

\section{Availability of data and materials}

In this study, we utilized de-identified patients' data from a computerized database of a health maintenance organization. These data are collected as part of patients' clinical care and not for research purposes. Legal and ethical restrictions apply for secondary usage of these data in research. Our IRB approval is limited to using anonymous data, and accordingly, we received exemption from informed consent. We are not allowed to provide datasets to be publicly available. Given IRB and legal restrictions, we cannot provide any access to individual-level data. Readers may contact Dr. Khitam Muhsen (the corresponding author) for further information.

\section{Authors' contributions}

$\mathrm{KM}$, IE, VS, and GH planned the study. VS and GH assisted in the data abstraction from Maccabi Health Services. KM, IE, and SG were responsible for the data management and analysis. KM wrote the first draft. All authors reviewed and approved the manuscript.

\section{Ethics approval and consent to participate}

The study protocol was approved by the Helsinki committee of Assuta Medical Center and the ethics committee of Tel Aviv University. Since this was a retrospective study in which we used coded (anonymized) administrative data from electronic medical records, an exemption from informed consent was given by the Helsinki committee.

\section{Competing interests}

The authors declare that they have no competing interests.

\section{Publisher's Note}

Springer Nature remains neutral with regard to jurisdictional claims in published maps and institutional affiliations.

\section{Author details}

'Department of Epidemiology and Preventive Medicine, School of Public Health, Sackler Faculty of Medicine, Tel Aviv University, Ramat Aviv, 69978 Tel Aviv, Israel. ${ }^{2}$ Medical Informatics Division, Maccabi Health Services, Tel Aviv, Israel. 


\section{Received: 10 August 2017 Accepted: 14 December 2017} Published online: 02 January 2018

\section{References}

1. Nomura A, Stemmermann GN, Chyou PH, Perez-Perez Gl, Blaser MJ. Helicobacter pylori infection and the risk for duodenal and gastric ulceration. Ann Intern Med. 1994;120(12):977-81.

2. Suerbaum S, Michetti P. Medical progress: Helicobacter pylori infection. $N$ Engl J Med. 2002;347(15):1175-86. https://doi.org/10.1056/Nejmra020542.

3. Nomura A, Stemmermann GN, Chyou PH, Kato I, Perezperez Gl, Blaser MJ. Helicobacter pylori infection and gastric carcinoma among Japanese Americans in Hawaii. N Engl J Med. 1991;325(16):1132-6. https://doi.org/10.1056/Nejm199110173251604.

4. Webb PM, Law M, Varghese C, Forman D, Yuan JM, Yu M, et al. Gastric cancer and Helicobacter pylori: a combined analysis of 12 case control studies nested within prospective cohorts. Gut. 2001;49(3):347-53.

5. Lam SK. Aetiological factors of peptic ulcer: perspectives of epidemiological observations this century. J Gastroenterol Hepatol. 1994;9(Suppl 1):S93-8.

6. Watabe H, Mitsushima T, Yamaji Y, Okamoto M, Wada R, Kokubo T, et al. Predicting the development of gastric cancer from combining Helicobacter pylori antibodies and serum pepsinogen status: a prospective endoscopic cohort study. Gut. 2005;54(6):764-8. https://doi.org/10.1136/gut.2004.055400.

7. Torre LA, Bray F, Siegel RL, Ferlay J, Lortet-Tieulent J, Jemal A. Global cancer statistics, 2012. CA Cancer J Clin. 2015;65(2):87-108. https://doi. org/10.3322/caac.21262.

8. de Martel C, Parsonnet J. Helicobacter pylori infection and gender: a metaanalysis of population-based prevalence surveys. Dig Dis Sci. 2006;51(12): 2292-301. https://doi.org/10.1007/s10620-006-9210-5.

9. Wang YK, Kuo FC, Liu CJ, MC W, Shih HY, Wang SS, et al. Diagnosis of Helicobacter pylori infection: current options and developments. World J Gastroenterol. 2015;21(40):11221-35. https://doi.org/10.3748/wjg.v21.i40.11221.

10. Gisbert JP, Pajares JM. Review article: $13 \mathrm{C}$-urea breath test in the diagnosis of Helicobacter pylori infection-a critical review. Aliment Pharmacol Ther 2004;20(10):1001-17. https://doi.org/10.1111/j.1365-2036.2004.02203.x.

11. Ferwana M, Abdulmajeed I, Alhajiahmed A, Madani W, Firwana B, Hasan R, et al. Accuracy of urea breath test in Helicobacter pylori infection: meta-analysis. World J Gastroenterol. 2015;21(4):1305-14. https://doi.org/10.3748/wjg.v21.i4.1305.

12. Malfertheiner P, Megraud F, O'Morain CA, Gisbert JP, Kuipers EJ, Axon AT, et al. Management of Helicobacter pylori infection - the Maastricht V/Florence Consensus Report. Gut. 2017;66(1):6-30. https://doi.org/10.1136/gutjnl-2016312288.

13. Graham DY, Klein PD, Evans DJ Jr, Evans DG, Alpert LC, Opekun AR, et al. Campylobacter pylori detected noninvasively by the 13C-urea breath test. Lancet. 1987:1(8543):1174-7.

14. Perri F, Clemente R, Pastore M, Quitadamo M, Festa V, Bisceglia M, et al. The 13C-urea breath test as a predictor of intragastric bacterial load and severity of Helicobacter pylori gastritis. Scand J Clin Lab Invest. 1998;58(1):19-27.

15. Chang MC, Chang YT, Sun CT, MS W, Wang HP, Lin JT. Quantitative correlation of Helicobacter pylori stool antigen ( $\mathrm{HpSA}$ ) test with 13C-urea breath test (13C-UBT) by the updated Sydney grading system of gastritis. Hepato-Gastroenterology. 2002;49(44):576-9.

16. Sheu BS, Lee SC, Yang HB, Lin XZ. Quantitative result of $\mathrm{C}-13$ urea breath test at 15 minutes may correlate with the bacterial density of $\mathrm{H}$. pylori in the stomach. Hepato-Gastroenterology. 1999;46(27):2057-62.

17. Zagari RM, Pozzato P, Martuzzi C, Fuccio L, Martinelli G, Roda E, et al. 13Curea breath test to assess Helicobacter pylori bacterial load. Helicobacter. 2005;10(6):615-9. https://doi.org/10.1111/j.1523-5378.2005.00358.x

18. Kobayashi D, Eishi Y, Ohkusa T, Ishige ST, Minami J, et al. Gastric mucosal density of Helicobacter pylori estimated by real-time PCR compared with results of urea breath test and histological grading. J Med Microbiol. 2002; 51(4):305-11. https://doi.org/10.1099/0022-1317-51-4-305.

19. Shmuely H, Yahav J, Samra Z, Chodick G, Ofek I. Elevated $13 \mathrm{C}$ urea breath test values females infected with Helicobacter pylori. Dig Dis Sci. 2007;52(2): 402-4. https://doi.org/10.1007/s10620-006-9590-6.

20. Zevit N, Niv Y, Shirin H, Shamir R. Age and gender differences in urea breath test results. Eur J Clin Investig. 2011;41(7):767-72. https://doi.org/10. 1111/j.1365-2362.2010.02467.x.

21. Moshkowitz M, Horowitz N, Beit-Or A, Halpern Z, Santo E. Gender-associated differences in urea breath test for Helicobacter pylori infection referrals and results among dyspeptic patients. World J Gastrointest Pathophysiol. 2012; 3(3):80-4. https://doi.org/10.4291/wjgp.v3.i3.80
22. Marinho FP, Trindade OR, Ferreira KN, Amaral LA, Coelho LGV. 13C-urea breath test values: a large database study focusing at gender differences. In: Helicobacter, editor. XXVth International Workshop on Helicobacter and Related Bacteria in Chronic Digestive Inflammation and Gastric Cancer; 13-15 September 2012; Ljubljana,: European Helicobacter Study Group; 2012. p. 92.

23. Israel Centeral Bureau of Statistics. Characterization and classification of local authorities by the socio-economic level of the population 2006. 2009.

24. Prewett EJ, Smith JT, Nwokolo CU, Sawyerr AM, Pounder RE. Twenty-four hour intragastric acidity and plasma gastrin concentration profiles in female and male subjects. Clin Sci. 1991;80(6):619-24.

25. Clyne M, Labigne A, Drumm B. Helicobacter pylori requires an acidic environment to survive in the presence of urea. Infect Immun. 1995; 63(5):1669-73.

26. Scott DR, Marcus EA, Weeks DL, Sachs G. Mechanisms of acid resistance due to the urease system of Helicobacter pylori. Gastroenterology. 2002;123(1): 187-95. https://doi.org/10.1053/gast.2002.34218.

27. Sachs G, Weeks DL, Melchers K, Scott DR. The gastric biology of Helicobacter pylori. Annu Rev Physiol. 2003;65:349-69. https://doi.org/10. 1146/annurev.physiol.65.092101.142156.

28. Crabtree JE, Court M, Aboshkiwa MA, Jeremy AH, Dixon MF, Robinson PA. Gastric mucosal cytokine and epithelial cell responses to Helicobacter pylori infection in Mongolian gerbils. J Pathol. 2004;202(2):197-207. https://doi. org/10.1002/path.1498.

29. Shore R, Bjorne H, Omoto Y, Siemiatkowska A, Gustafsson JA, Lindblad $M$, et al. Sex differences and effects of oestrogen in rat gastric mucosal defence. W J Gastroenterol. 2017;23(3):426-36. https://doi.org/10.3748/ wjg.v23.i3.426.

30. Matthews GM, Cummins AG, Lawrence A, Johnson B, Campbell F, Butler RN. 13C-urea breath test: reproducibility and association with the severity of Helicobacter pylori-associated antral gastritis. J Gastroenterol Hepatol. 2005; 20(2):270-4. https://doi.org/10.1111/j.1440-1746.2005.03547.x.

31. Ruiz B, Correa P, Fontham ET, Ramakrishnan T. Antral atrophy, Helicobacter pylori colonization, and gastric pH. Am J Clin Pathol. 1996;105(1):96-101.

32. Muhsen K, Jurban M, Goren S, Cohen D. Incidence, age of acquisition and risk factors of Helicobacter pylori infection among Israeli Arab infants. J Trop Pediatr. 2012:58(3):208-213. doi:fmr068 [pii]https://doi. org/10.1093/tropej/fmr068.

33. Muhsen K, Nir A, Spungin-Bialik A, Bassal R, Goren S, Cohen D. Interaction among ethnicity, socioeconomic status, and Helicobacter pylori seroprevalence in Israeli children and adolescents. J Pediatr Gastroenterol Nutr. 2011;53(5):524-7. https://doi.org/10.1097/MPG.0b013e31822676ca.

34. Roberts SB, Dallal GE. Energy requirements and aging. Public Health Nutr. 2005;8(7A):1028-36.

35. Liu HY, YF L, Chen WJ. Predictive equations for basal metabolic rate in Chinese adults: a cross-validation study. J Am Diet Assoc. 1995;95(12): 1403-8. https://doi.org/10.1016/S0002-8223(95)00369-X

36. Moshkowitz M, Brill S, Konikoff FM, Averbuch M, Arber N, Halpern Z Additive deleterious effect of smoking on gastroduodenal pathology and clinical course in Helicobacter pylori-positive dyspeptic patients. Isr Med Assoc J. 2000;2(12):892-5.

37. Endoh K, Leung FW. Effects of smoking and nicotine on the gastric mucosa: a review of clinical and experimental evidence. Gastroenterology. 1994; 107(3):864-78.

38. Fontham E, Zavala D, Correa P, Rodriguez E, Hunter F, Haenszel W, et al. Diet and chronic atrophic gastritis: a case-control study. J Natl Cancer Inst. 1986;76(4):621-7.

39. Ladeiras-Lopes R, Pereira AK, Nogueira A, Pinheiro-Torres T, Pinto I, SantosPereira $\mathrm{R}$, et al. Smoking and gastric cancer: systematic review and metaanalysis of cohort studies. Cancer Causes Control. 2008;19(7):689-701. https://doi.org/10.1007/s10552-008-9132-y.

40. Muhsen K, Goren S, Cohen D. Helicobacter pylori infection in early childhood and growth at school age. Helicobacter. 2015;20(6):410-7. https://doi.org/10.1111/hel.12227.

41. Muhsen K, Cohen D, Spungin-Bialik A, Shohat T. Seroprevalence, correlates and trends of Helicobacter pylori infection in the Israeli population. Epidemiol Infect 2012;140(7):1207-1214. doi:S0950268811002081 [pii] https:// doi.org/10.1017/S0950268811002081.

42. Muhsen K, Athamna A, Athamna M, Spungin-Bialik A, Cohen D. Prevalence and risk factors of Helicobacter pylori infection among healthy 3- to 5-yearold Israeli Arab children. Epidemiol Infect 2006;134(5):990-996. doi: S0950268806006030 [pii] https://doi.org/10.1017/S0950268806006030. 
43. Steinberg M, Becklake MR. Socio-environmental factors and lung function. S Afr Med J. 1986;70(5):270-4.

44. Shohaimi S, Welch A, Bingham S, Luben R, Day N, Wareham N, et al. Area deprivation predicts lung function independently of education and social class. Eur Respir J. 2004;24(1):157-61.

45. Schmulson M, Adeyemo M, Gutierrez-Reyes G, Charua-Guindic L, FarfanLabonne B, Ostrosky-Solis F, et al. Differences in gastrointestinal symptoms according to gender in Rome II positive IBS and dyspepsia in a Latin American population. Am J Gastroenterol. 2010;105(4):925-32. https://doi. org/10.1038/ajg.2010.58.

46. Drossman DA, Li Z, Andruzzi E, Temple RD, Talley NJ, Thompson WG, et al. U.S. householder survey of functional gastrointestinal disorders. Prevalence, sociodemography, and health impact. Dig Dis Sci. 1993;38(9):1569-80.

47. Moayyedi P, Chalmers DM, Axon ATR. Patient factors that predict failure of omeprazole, clarithromycin, and tinidazole to eradicate Helicobacter pylori. $J$ Gastroenterol. 1997;32(1):24-7. https://doi.org/10.1007/Bf01213292.

48. Kim SE, Park MI, Park SJ, Moon W, Choi YJ, Cheon JH, et al. Trends in Helicobacter pylori eradication rates by first-line triple therapy and related factors in eradication therapy. Korean J Intern Med. 2015;30(6):801-7. https://doi.org/10.3904/kjim.2015.30.6.801.

49. Pan KF, Zhang L, Gerhard M, Ma JL, Liu WD, Ulm K, et al. A large randomised controlled intervention trial to prevent gastric cancer by eradication of Helicobacter pylori in Linqu County, China: baseline results and factors affecting the eradication. Gut. 2016;65(1):9-18 https://doi.org/10.1136/gutjinl-2015-309197.

50. Shmuely H, Yahav J, Samra Z, Chodick G, Koren R, Niv Y, et al. Effect of cranberry juice on eradication of Helicobacter pylori in patients treated with antibiotics and a proton pump inhibitor. Mol Nutr Food Res. 2007;51(6):74651. https://doi.org/10.1002/mnfr.200600281.

\section{Submit your next manuscript to BioMed Central and we will help you at every step:}

- We accept pre-submission inquiries

- Our selector tool helps you to find the most relevant journal

- We provide round the clock customer support

- Convenient online submission

- Thorough peer review

- Inclusion in PubMed and all major indexing services

- Maximum visibility for your research

Submit your manuscript at www.biomedcentral.com/submit

) Biomed Central 